\title{
İsolation of the $\mathrm{N}$-terminal globular protein domains from cartilage proteoglycans
}

\author{
Identification of $\mathbf{G 2}$ domain and its lack of interaction with hyaluronate and link protein
}

\author{
Amanda J. FOSANG and Timothy E. HARDINGHAM* \\ Biochemistry Division, Kennedy Institute of Rheumatology, Hammersmith, London W6 7DW, U.K.
}

\begin{abstract}
The $N$-terminal fragment $(\mathrm{G} 1-\mathrm{G} 2)$ of cartilage proteoglycan protein core contains two globular domains, binding region (G1) and a second globular domain (G2). G1-G2 was isolated after mild trypsin digestion of purified proteoglycan aggregates followed by chromatography first on Sepharose CL-2B under associative conditions and then on a TSK-4000 column in $4 \mathrm{M}$-guanidinium chloride. It migrated as a single band (apparent $M_{\mathrm{r}}$ 150000) on SDS/polyacrylamide-gel electrophoresis. G2 was isolated by V8-proteinase digestion of G1-G2 followed by aggregation of the G1-containing fragments with hyaluronate and chromatography on TSK-4000. It migrated as a single band on SDS/polyacrylamide-gel electrophoresis of apparent $M_{\mathrm{r}} 66000$ after digestion with keratanase. G2 did not interact with proteoglycan monomer, hyaluronate, link protein or other extractable cartilage matrix proteins. A polyclonal antibody raised against G2 did not cross-react with G1 or link protein. These data show that, despite a high degree of sequence similarity, G1 and G2 do not share any functional properties nor have major antigenic sites in common.
\end{abstract}

\section{INTRODUCTION}

The major proteoglycan present in cartilage is a high$M_{\mathrm{r}}$ aggregating species that contains chondroitin sulphate and keratan sulphate chains, which are located on specific regions of the core protein (Hardingham et al., 1986). The chondroitin sulphate chains (about 100, $M_{\mathrm{r}}$ 15000-25000) are restricted to a long extended region of the protein core, whereas the keratan sulphate chains (about 50, $M_{\mathrm{r}}$ 5000-15000) are distributed more widely throughout the core protein, some on the long chondroitin sulphate-rich region, and on an adjacent keratan sulphate-rich region, but also towards the $N$-terminus around the globular domains G1 and G2 (see below). Some $O$-linked and $N$-linked oligosaccharides are also present.

Three distinct globular domains have been identified in the cartilage proteoglycan core protein by using rotaryshadowing techniques (Wiedemann et al., 1984; Paulsson et al., 1987; Mörgelin et al., 1988), peptide mapping and sequence analysis (Sai et al., 1986; Doege et al., 1986, 1987; Neame et al., 1987; Oldberg et al., 1987) (Fig. 1). These studies revealed two globular domains, G1 and G2 towards the $\mathrm{N}$-terminus of the protein core and a $\mathrm{C}$ terminal protein domain (G3). The G3 domain $\left(M_{\mathrm{r}}\right.$ 26000) contains ten cysteine residues and parts of it have sequence similarity to a hepatic lectin (Doege et al., 1986; Sai et al., 1986; Oldberg et al., 1987; Halberg et al., 1988 ) and to a $\beta$-component found in complement proteins (Patthy, 1987).

The $N$-terminal domain $\mathrm{G} 1$ contains a hyaluronatebinding site (Hardingham et al., 1986; Paulsson et al., 1987), and thus represents the region that is involved in specific interactions with hyaluronate and link protein to form stable aggregates of high $M_{\mathrm{r}}$ (Hardingham \& Muir,
1972; Heinegård \& Hascall, 1974; Hardingham et al., 1976). G1 from pig laryngeal-cartilage proteoglycan contains both $O$-linked and $N$-linked oligosaccharides, some keratan sulphate, but no chondroitin sulphate, and has an apparent $M_{\mathrm{r}}$ of 66500 (Bonnet et al., 1985). The results of rotary shadowing show that the $\mathrm{G} 2$ domain is joined to G1 by a short extended segment (Paulsson et al., 1987) of fixed length $(25 \mathrm{~nm})$. G2 shows strong sequence similarity to both link protein and G1 (Neame et al., 1987; Doege et al., 1987). The $N$-terminal regions of $\mathrm{Gl}$ and link protein show sequence similarity to an immunoglobulin variable-region fold (Bonnet et al., 1986; Perkins et al., 1989), whereas the more $C$-terminal segments contain a homologous tandem repeat structure. Link protein and Gl thus contain similar structural elements, whereas G2 contains a further copy of the tandem repeat without the immunoglobulin fold. Although link protein and G1 are known to have functions in proteoglycan aggregation, there is no known function for $\mathrm{G} 2$.

In the present study we describe the isolation of double-globe (G1-G2) fragment and G2 domain from pig laryngeal-cartilage proteoglycan aggregates, and present evidence that $\mathrm{G} 1$ and $\mathrm{G} 2$ do not share functional properties.

\section{MATERIALS AND METHODS}

\section{Materials}

All reagents were analytical grade except for guanidinium chloride (BDH Chemicals, Poole, Dorset, U.K.), which was purified with activated charcoal (Norit GSX; Hopkin and Williams, Chadwell Heath, Essex, U.K.).

* To whom correspondence should be addressed. 


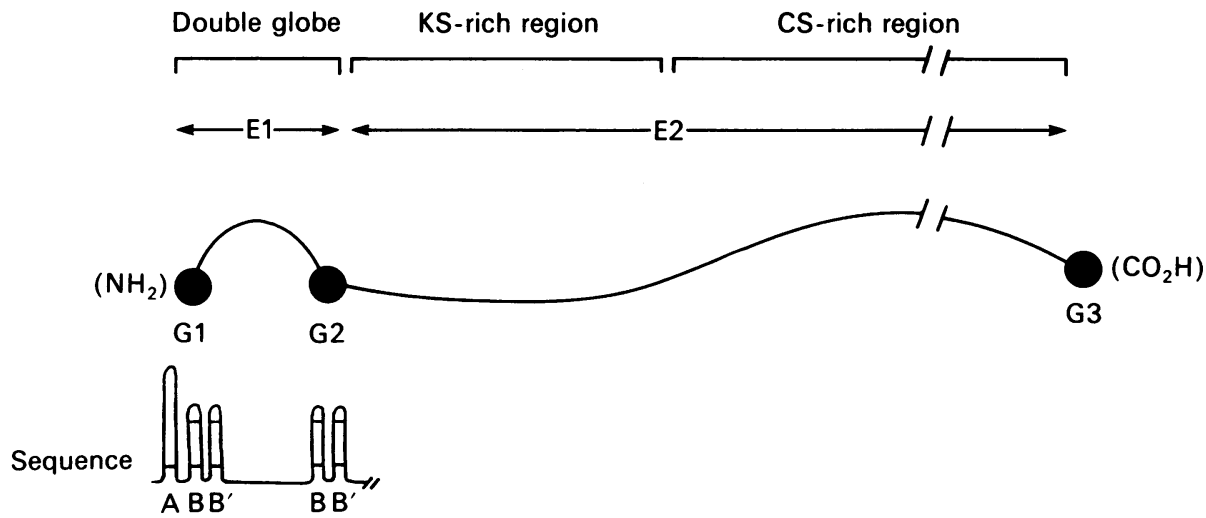

Fig. 1. Schematic representation of proteoglycan core protein structure

The globular hyaluronate-binding region (G1) is joined to a second globular domain, G2, by a short extended region (E1). The region designated E2 represents the long extended region of the core protein that bears most of the keratan sulphate (KS) chains including the keratan sulphate-rich region and all of the chondroitin sulphate (CS) chains. G3 represents the $C$-terminal globular domain. The Ig fold (A loop) and the two copies of the tandem repeat structures (B and B' loops) present in the G1 and G2 sequence are shown schematically.

Trypsin (diphenylcarbamoyl chloride-treated) (EC 3.4.21.4), 6-aminohexanoic acid, phenylmethanesulphonyl fluoride, disodium EDTA, benzamidine hydrochloride, bovine serum albumin (fraction V), V8 proteinase (Staphylococcus aureus strain 8), soya-bean trypsin inhibitor, 3,3'-diaminobenzidine tetrahydrochloride, anti-(mouse IgG) antibody-peroxidase and anti-(rabbit IgG) antibody-peroxidase conjugates, Staphylococcus aureus (Cowan strain) powdered cells and iodoacetamide were obtained from Sigma (London) Chemical Co. (Poole, Dorset, U.K.). Sepharose CL-2B, DEAE-Sephacel and Sephadex G-50 were obtained from Pharmacia (Uppsala, Sweden). TSK-3000 and TSK-4000 h.p.l.c. columns were obtained from Anachem (Luton, Beds., U.K.); Endo- $\beta$-D-galactosidase (keratanase) was obtained from Miles Laboratories (Slough, Berks., U.K.). Casein was obtained from Fisons Scientific Apparatus (Loughborough, Leics., U.K.) and skim-milk powder (Marvel) was commercially available. $\mathrm{Na}^{125} \mathrm{I}$ (IMS 30) was obtained from Amersham International (Amersham, Bucks., U.K.). Hyaluronate-Sepharose was a gift from Michael Holmes and Michael Bayliss of this Institute.

\section{Preparation of cartilage proteoglycan and collagen}

Proteoglycan aggregates extracted from pig laryngeal cartilage in $4 \mathrm{M}$-guanidinium chloride $/ 50 \mathrm{~mm}$-sodium acetate buffer, $\mathrm{pH} 5.8$, containing proteinase inhibitors were purified in a $\mathrm{CsCl}$ density gradient as described by Hardingham (1979). The gradients were cut into three equal fractions. Proteoglycans were isolated from the bottom fraction (A1), and fractions $\mathrm{A} 2$ and $\mathrm{A} 3$ containing other cartilage components were kept for interaction experiments (see below). Proteoglycan monomer (A1D1) and link protein were prepared from proteoglycan aggregate by fractionation in a dissociative $\mathrm{CsCl}$ density gradient (Hardingham, 1979) and link protein was further purified by chromatography on a TSK -3000 $(30 \mathrm{~cm} \times 2.1 \mathrm{~cm})$ column in $4 \mathrm{M}$-guanidinium chloride. Type II collagen from pig laryngeal cartilage was prepared by solubilization with pepsin (Miller, 1972) and salt precipitation as described by Grant et al. (1988).

\section{Preparation of double-globe domain (G1-G2)}

Purified freeze-dried proteoglycan aggregate (A1) was dissolved overnight in $0.1 \mathrm{M}$-Tris/acetate buffer, $\mathrm{pH} 7.3$ $(15 \mathrm{mg} / \mathrm{ml})$, then digested with trypsin for $2 \mathrm{~h}$ at $37^{\circ} \mathrm{C}$ at a final concentration of $3 \mu \mathrm{g}$ of trypsin $/ 150 \mathrm{mg}$ of $\mathrm{A} 1$. The reaction was stopped by the addition of a 100 -fold excess of trypsin inhibitor and concentrated by partial freeze-drying to one-third volume for chromatography on a Sepharose CL-2B column $(2 \mathrm{~cm} \times 140 \mathrm{~cm})$ in $0.5 \mathrm{M}$ sodium acetate buffer, $\mathrm{pH} 6.8$, at $4{ }^{\circ} \mathrm{C}$. Fractions were assayed for binding region (G1), link protein and keratan sulphate by radioimmunoassay (see below), and for sulphated glycosaminoglycans by the dye-binding assay (Ratcliffe et al., 1988). The void-volume $\left(V_{0}\right)$ fractions were pooled, dialysed against distilled water and freezedried. The sample was then dissolved in $4 \mathrm{~m}$-guanidinium chloride/1 mm-sodium EDTA/50 mM-sodium acetate buffer, $\mathrm{pH} 5.8$, and chromatographed on a TSK-4000 column $(0.75 \mathrm{~cm} \times 60 \mathrm{~cm})$ eluted in the same buffer to separate the G1-G2 fragment from G1 and link protein. Fractions were analysed for link protein, G1 and keratan sulphate by radioimmunoassay (see below), and the pooled fractions containing G1-G2 were rechromatographed on the same column, dialysed and freeze-dried.

\section{Preparation of globular domain G2}

Purified G1-G2 fragment $(520 \mu \mathrm{g})$ was dissolved in $10 \mathrm{~mm}$-EDTA/0.1 $\mathrm{M}$-Tris/HCl buffer, $\mathrm{pH} \mathrm{8.0,} \mathrm{and}$ digested for $1 \mathrm{~h}$ at $37^{\circ} \mathrm{C}$ with 0.452 unit of V8 proteinase in a total volume of $416 \mu l$. The digestion was stopped by boiling for $5 \mathrm{~min}$ and $10 \mu \mathrm{l}$ of hyaluronate $(10 \mathrm{mg} / \mathrm{ml})$ was added, and the mixture was kept overnight at $4{ }^{\circ} \mathrm{C}$. Half the sample was applied to a TSK -4000 column $(30 \mathrm{~cm} \times 0.75 \mathrm{~cm})$ eluted in phosphate-buffered saline $\left(0.123 \mathrm{M}-\mathrm{NaCl} / 10 \mathrm{~mm}-\mathrm{Na}_{2} \mathrm{HPO}_{4} / 3.16 \mathrm{~mm}-\mathrm{K} \mathrm{H}_{2} \mathrm{PO}_{4}\right.$ buffer, pH 7.4), and monitored for absorbance at $280 \mathrm{~nm}$. The fractions were assayed for G1 and keratan sulphate epitopes (see below). A u.v.-absorbing peak (containing G2) that was included on the column and that did not contain any G1 epitope was pooled and purified by rechromatography on the same column in the presence of extra hyaluronate $(100 \mu \mathrm{g})$. The included 
G2 peak was pooled, dialysed and freeze-dried. In some instances $\mathrm{G} 1-\mathrm{G} 2$ was digested with keratanase $(0.07 \mathrm{unit} / \mathrm{mg}$ in $50 \mathrm{~mm}$-Tris $/ \mathrm{HCl} / 50 \mathrm{~mm}$-sodium acetate

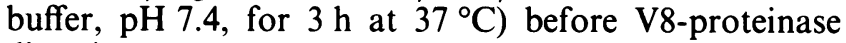
digestion.

With some G2 preparations an additional ion-exchange purification step was included. G2 samples (about $0.5 \mathrm{mg}$ ) were dissolved in $200 \mu \mathrm{l}$ of $0.2 \mathrm{M}-\mathrm{NaCl} / 50 \mathrm{~mm}-$ sodium acetate buffer, pH 6.8, and applied to a DEAESephacel column $(0.9 \mathrm{~cm} \times 1.4 \mathrm{~cm})$. The sample was eluted with $5 \mathrm{ml}$ each of $0.2 \mathrm{M}-, 0.4 \mathrm{M}-, 0.6 \mathrm{M}-, 0.8 \mathrm{M}-$, $1.0 \mathrm{M}-, 1.5 \mathrm{M}-$ and $2.0 \mathrm{M}-\mathrm{NaCl}$, all in $50 \mathrm{~mm}$-sodium acetate buffer, $\mathrm{pH}$ 6.8. Each $5 \mathrm{ml}$ fraction was assayed for $\mathrm{G} 2$ and keratan sulphate epitope, and the purified G2 (see below) fraction was dialysed and freeze-dried.

Immunoprecipitation of V8-proteinase-digestion products

Portions $\left(10^{5}\right.$ c.p.m. $\left./ 10 \mu \mathrm{l}\right)$ of ${ }^{125} \mathrm{I}$-labelled control or V8-proteinase-digested G1-G2 samples were mixed with $15 \mu \mathrm{l}$ of anti-G1 serum (the amount shown to produce maximum precipitation on a titration curve) and incubated overnight at $4^{\circ} \mathrm{C}$ in incubation buffer composed of

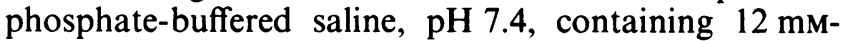
deoxycholate, $0.1 \%$ Nonidet, $0.1 \%$ bovine serum albumin and $0.03 \% \mathrm{NaN}_{3}$. Antibody-antigen complexes and free antibody were precipitated by the addition of $200 \mu \mathrm{l}$ of $10 \%(\mathrm{w} / \mathrm{v})$ Staphylococcus aureus dried cells, and were separated from the supernatants by centrifugation. Each precipitate was extracted twice by boiling for $5 \mathrm{~min}$ in $50 \mu \mathrm{l}$ of $10 \mathrm{~mm}$-EDTA/0.1 $\mathrm{M}$-Tris $/ \mathrm{HCl}$ buffer, $\mathrm{pH} 8$, and $1 \mu \mathrm{l}$ of $1 \%(\mathrm{w} / \mathrm{v})$ SDS and the extracts were combined.

\section{Iodination and radioimmunoassays}

Iodination of $\mathrm{G} 1, \mathrm{G} 2, \mathrm{G} 1-\mathrm{G} 2$, link protein and proteoglycan monomer was performed as described by Greenwood et al. (1963) with chloramine-T as the oxidizing agent. Approx. $5 \mu \mathrm{g}$ of protein was iodinated with $0.3 \mathrm{mCi}$ of $\mathrm{Na}^{125} \mathrm{I}$, and the iodinated product was stored at $-20^{\circ} \mathrm{C}$. Radioimmunoassays for $\mathrm{Gl}$ and link protein were performed with polyclonal antisera and for keratan sulphate with the monoclonal antibody MZ-15 as described previously (Ratcliffe \& Hardingham, 1983; Zanetti et al., 1985). A competitive radioimmunoassay for G2 was developed with the polyclonal antiserum raised in the present study. The assay method was similar to that previously described (Ratcliffe \& Hardingham, 1983) but with ${ }^{125}$ I-labelled G1-G2 as antigen.

\section{Determination of sulphated glycosaminoglycans}

The concentration of sulphated glycosaminoglycans in Sepharose CL-2B fractions was determined by a modification of the dye-binding assay (Farndale et al., 1982) carried out in 96-well micro-titre plates (Ratcliffe et al., 1988). Portions $(40 \mu \mathrm{l})$ of samples or standards in $0.5 \mathrm{M}$ sodium acetate buffer, $\mathrm{pH} 6.8$, were placed in wells and the plates were read at $600 \mathrm{~nm}$ on a Bio-Rad model 2550 EIA reader immediately after the addition of $250 \mu \mathrm{l}$ of dye solution.

\section{SDS/polyacrylamide-gel electrophoresis, immunoblotting and autoradiography}

Electrophoresis was performed in $5 \%$ polyacrylamide gels as described by Fairbanks et al. (1971). In some instances samples were reduced by boiling in the presence of $2 \mu \mathrm{l}$ of 2 -mercaptoethanol before being loaded on to the gels. Protein bands were detected by silver staining (Morrissey, 1981).

Immunoblotting of protein antigens was performed by a modification of the method of DeBlas \& Cherwinski (1983). Proteins were electrophoretically transferred from polyacrylamide slab gels on to nitrocellulose sheets (Schleicher und Schüll, Dassel, West Germany) overnight at $80 \mathrm{~mA}$ at $4{ }^{\circ} \mathrm{C}$ in transfer buffer ( $2 \mathrm{~mm}$-EDTA/40 mMTris $/ \mathrm{HCl} / 20 \mathrm{~mm}$-sodium acetate buffer, $\mathrm{pH} 7.4)$. The nitrocellulose sheets were blocked with either $2 \%(\mathrm{w} / \mathrm{v})$ casein or $5 \%(\mathrm{w} / \mathrm{v})$ skim-milk powder in phosphatebuffered saline. Antibody dilutions were $1: 1000$ for antiG1 antibody, 1:500 for anti-G2 antibody and 1:500 for anti-(link protein) antibody. After six washes (2-5 min) in phosphate-buffered saline, sheets were incubated in 1:1000 dilution of anti-(mouse IgG) antibodyperoxidase or anti-(rabbit IgG) antibody-peroxidase conjugate for $1 \mathrm{~h}$ at room temperature. The peroxidase reaction was developed in the dark as described by DeBlas \& Cherwinski (1983) with 3,3'-diaminobenzidine tetrahydrochloride as substrate.

$\mathrm{Slab}$ gels containing ${ }^{125} \mathrm{I}$-labelled material were vacuum-dried and exposed for $16-48 \mathrm{~h}$ at $-70^{\circ} \mathrm{C}$ to $\mathrm{X}$ Omat S X-ray film (Kodak, Hemel Hempstead, Herts., U.K.). Developed X-ray films were scanned on a Shimadzu CS-930 dual-wavelength scanner.

\section{Preparation of anti-G2 serum}

Antisera were raised in rabbits (Ratcliffe \& Hardingham, 1983) by primary injection of $160 \mu \mathrm{g}$ of $\mathrm{G} 2$ in Freund's complete adjuvant followed by booster injections of $30-80 \mu \mathrm{g}$ of $\mathrm{G} 2$ in Freund's incomplete adjuvant at approx. 3-week intervals. Keratanase-digested G2 was used for some later boosts. Antisera were collected 10-12 days after each boost.

\section{G1-G2 and G2 interaction experiment}

The proportion of ${ }^{125}$ I-labelled G1-G2 that had retained its ability to bind to hyaluronate after iodination was selected by passing a portion $\left(4 \times 10^{6}\right.$ c.p.m. $)$ over a $200 \mu \mathrm{l}$ hyaluronate-Sepharose column in $1 \mathrm{M}-\mathrm{NaCl} /$ $50 \mathrm{~mm}$-sodium acetate buffer, $\mathrm{pH} \mathrm{6.8}$, and eluting the fraction $(38 \%)$ that bound to the gel with $4 \mathrm{M}$-guanidinium chloride in the same buffer. ${ }^{125}$ I-labelled G1-G2 or ${ }^{125} \mathrm{I}$-labelled G2 (keratanase-digested) was then mixed with either $125 \mu \mathrm{g}$ of proteoglycan monomer with or without $10 \mu \mathrm{g}$ of hyaluronate with or without $5 \mu \mathrm{g}$ of link protein, or $100 \mu \mathrm{g}$ of A 2 fraction, or $100 \mu \mathrm{g}$ of A3 fraction, or $100 \mu \mathrm{g}$ of type II collagen, in a total volume of $400 \mu \mathrm{l}$. Each sample was made up to a final concentration of $4 \mathrm{M}$-guanidinium chloride in order to dissociate all components and then dialysed against several changes of phosphate-buffered saline to permit reassociation. For testing interaction with type II collagen samples were mixed directly with it in phosphate-buffered saline. Each sample was chromatographed on an associative TSK -4000 column, and the fractions were assayed for radioactivity and total glycosaminoglycan content where appropriate.

Identical experiments were performed with $10 \mu \mathrm{g}$ of non-iodinated $\mathrm{G} 2$ that had been digested with keratanase and then mixed with either $250 \mu \mathrm{g}$ of proteoglycan monomer with or without $40 \mu \mathrm{g}$ of hyaluronate with or without $10 \mu \mathrm{g}$ of link protein, or $200 \mu \mathrm{g}$ of $\mathrm{A} 2$ fraction, or $200 \mu \mathrm{g}$ of A 3 fraction, or $200 \mu \mathrm{g}$ of type II collagen, in a total volume of $200 \mu \mathrm{l}$. These samples were eluted from 
a Sepharose CL-2B column $(12.5 \mathrm{~cm} \times 0.8 \mathrm{~cm})$ in $0.123 \mathrm{M}$ -

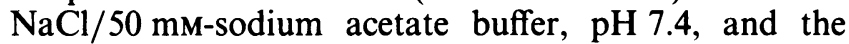
fractions were assayed for. G2 epitope.

\section{RESULTS}

Previous results have shown that trypsin cleaves the proteoglycan protein core (Fig. 1) at many sites, but that the globular binding-region domain and link protein are resistant to digestion if they are part of a stable aggregate structure bound to hyaluronate (Heinegård \& Hascall, 1974; Bonnet et al., 1985). In preliminary experiments less extensive digestion was shown to release a coreprotein fragment containing two globular domains, which were identified by rotary-shadowing electron microscopy (Paulsson et al., 1987). In the present study this double-globe fragment was prepared by mild trypsin digestion of pig laryngeal-cartilage proteoglycan aggregates. Fractionation of the digest on Sepharose CL-2B separated all the proteoglycan fragments remaining

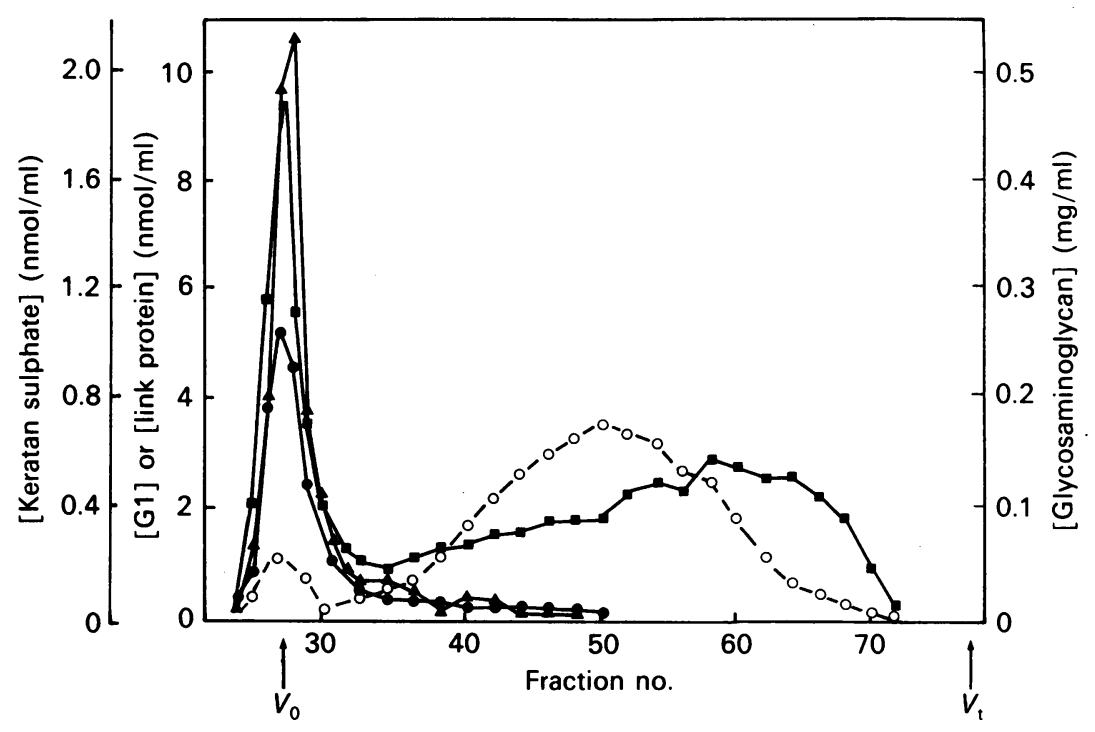

Fig. 2. Sepharose CL-2B chromatography of trypsin-digested proteoglycan aggregate

Proteoglycan aggregate was digested with trypsin as described in the Materials and methods section, and the digest was chromatographed on Sepharose CL-2B in $0.5 \mathrm{M}$-sodium acetate buffer, $\mathrm{pH} 6.8$, at $4{ }^{\circ} \mathrm{C}$. Fractions were assayed for sulphated glycosaminoglycans by the dye-binding assay $(O)$ and for $G 1(\boldsymbol{O})$, link protein $(\boldsymbol{\Delta})$ and keratan sulphate $(\boldsymbol{\square})$ by radioimmunoassays. The keratan sulphate epitope was determined by competition with a purified proteoglycan monomer from pig laryngeal cartilage and results are expressed in mol of proteoglycan (Zanetti et al., 1985). The $V_{0}$ fractions were pooled for chromatography on a dissociative TSK-4000 column (Fig. 3).

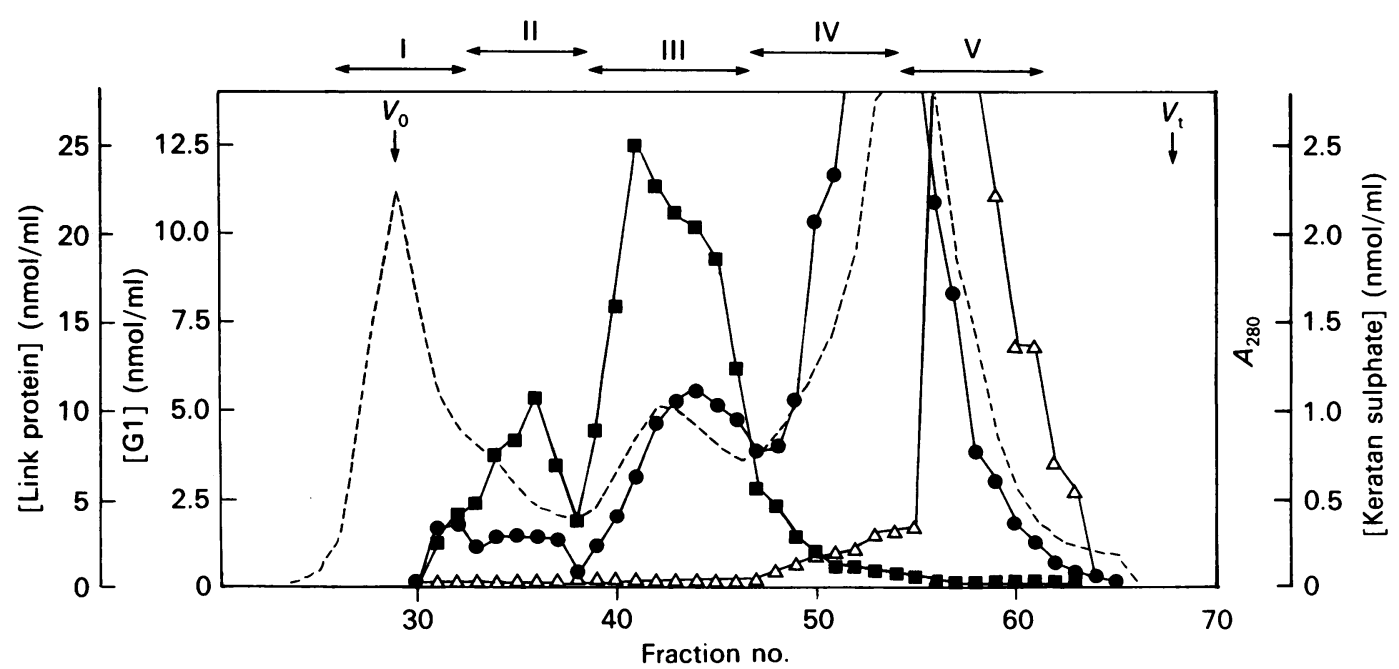

Fig. 3. TSK-4000 h.p.l.c. of hyaluronate-bound trypsin-digested proteoglycan aggregate after mild trypsin digestion

Hyaluronate-bound fractions recovered in the $V_{0}$ fraction of a Sepharose CL-2B chromatography (Fig. 2) after mild trypsin digestion were dissociated in $4 \mathrm{M}$-guanidinium chloride and fractionated on a TSK- 4000 h.p.l.c. column as described in the Materials and methods section. The $A_{280}(---)$ was measured across the profile and portions of each fraction were diluted $1: 100$ and assayed for Gl $(\bigcirc)$, link protein $(\triangle)$ and keratan sulphate $(\square)$ (see Fig. 2) by radioimmunoassay. 
bound to hyaluronate in the $V_{0}$ fraction of the column from the large glycosaminoglycan-rich fragments cleaved from the proteoglycans. Radioimmunoassays showed that the bound fraction contained all the binding region (G1) and link protein together with $30 \%$ of the total keratan sulphate epitope, but only $4-10 \%$ of the total glycosaminoglycans (Fig. 2).

The hyaluronate-bound fraction was dissociated in 4 m-guanidinium chloride and fractionated by size exclusion on a TSK -4000 h.p.l.c. column (Fig. 3). Five main protein peaks were detected, which were identified by radioimmunoassays for $\mathrm{Gl}$, keratan sulphate and link protein. In addition to a fraction of similar size to trypsin-prepared binding region (G1) peak IV, there was also a peak (III) of much higher $M_{\mathrm{r}}$ that contained G1, which was shown by rotary-shadowing electron microscopy to contain a double-globe structure (Paulsson et al., 1987). After rechromatography on the same column this fraction migrated as a single broad band on SDS/5\%-polyacrylamide-gel electrophoresis with an apparent $M_{\mathrm{r}}$ of 150000 (Fig. 4). Although less than $50 \%$ of the total Gl was in this fraction, shorter digestion times did not increase the yield (results not shown). A larger fragment containing G1 was also present (peak II), which may correspond to G1-G2 with an additional protein core segment attached to it, but this has not been characterized further.

The iodinated G1-G2 fragment was immunoprecipitated by polyclonal anti-G1 serum and also by a monoclonal anti-(keratan sulphate) antibody, showing that the G1 epitopes survived iodination and that keratan sulphate was attached to the double-globe structure.

\section{V8-proteinase digestion of G1-G2}

The structure of the G1-G2 fragment was investigated by using V8 proteinase, which hydrolyses peptide and
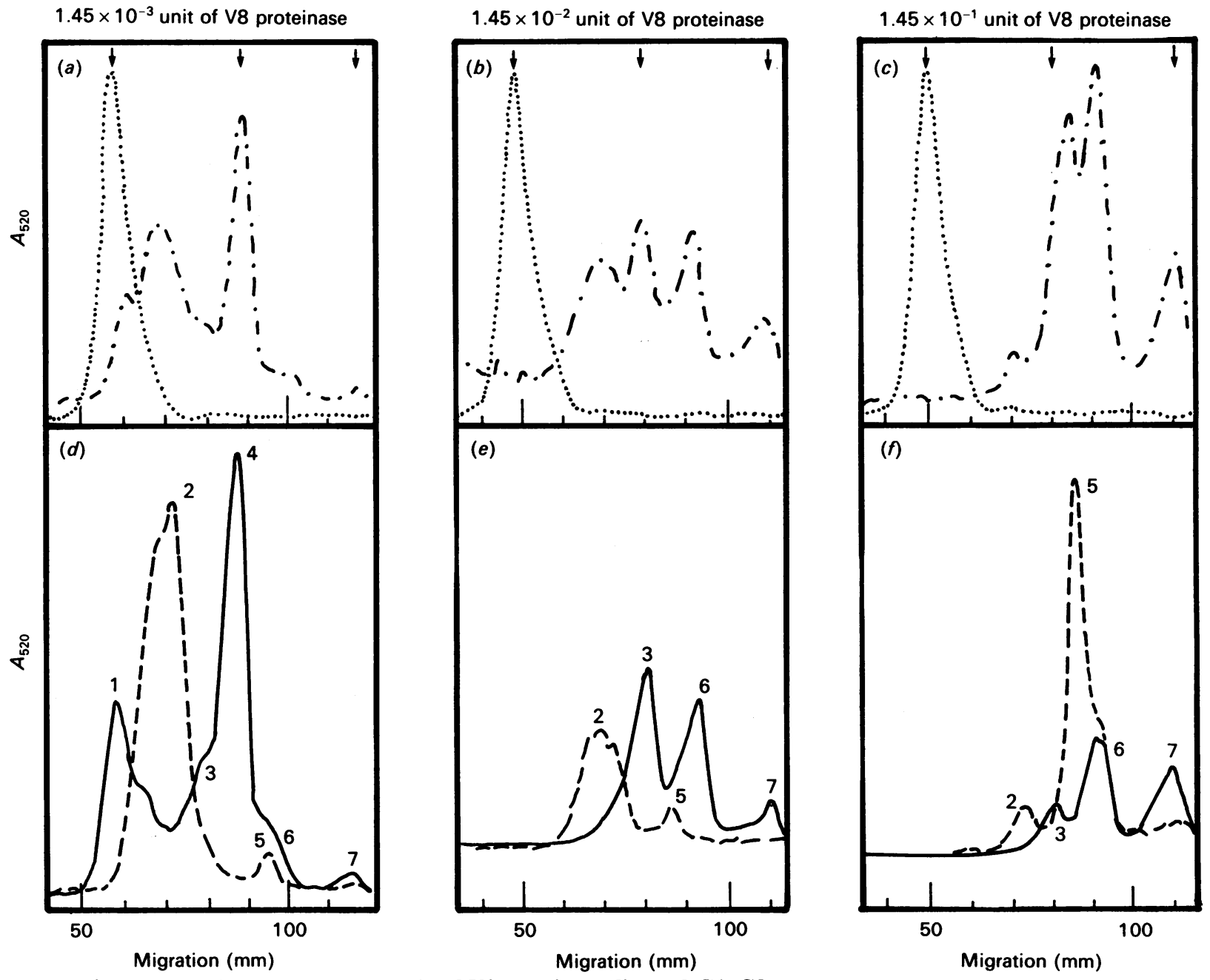

Fig. 4. SDS/polyacrylamide-gel electrophoresis of V8-proteinase-digested G1-G2

${ }^{125} \mathrm{I}$-labelled G1-G2 $(100 \mu \mathrm{l})$ was digested at $37^{\circ} \mathrm{C}$ for $1 \mathrm{~h}$ in $10 \mathrm{~mm}$-EDTA/0.1 $\mathrm{M}$-Tris/HCl buffer, $\mathrm{pH} 8.0$, with $1.45 \times 10^{-3}$, $1.45 \times 10^{-2}$ or $1.45 \times 10^{-1}$ unit of $\mathrm{V} 8$ proteinase $/ 200 \mu$ l digestion volume $(a-c)$. $\cdots \cdots$, Undigested G1-G2 (corresponding to fragment structure 0 in Fig. 5); -.-.-, digest products. After being boiled for 2 min, portions of each digest were immunoprecipitated with anti-G1 serum, and the ${ }^{125}$ I-labelled fragments present in the supernatants and pellets were separated as described in the text $(d-f)$. Portions of each digest and the corresponding supernatants (----, G1-negative) and precipitates (-, G1-positive) were subjected to SDS $/ 5 \%$-polyacrylamide-gel electrophoresis under non-reducing conditions. The profiles were obtained by scanning autoradiographs of the dried gels. Arrows at the top of each frame indicate $M_{\mathrm{r}}$ markers corresponding to $M_{\mathrm{r}} 150000,60000$ and 20000 respectively. 


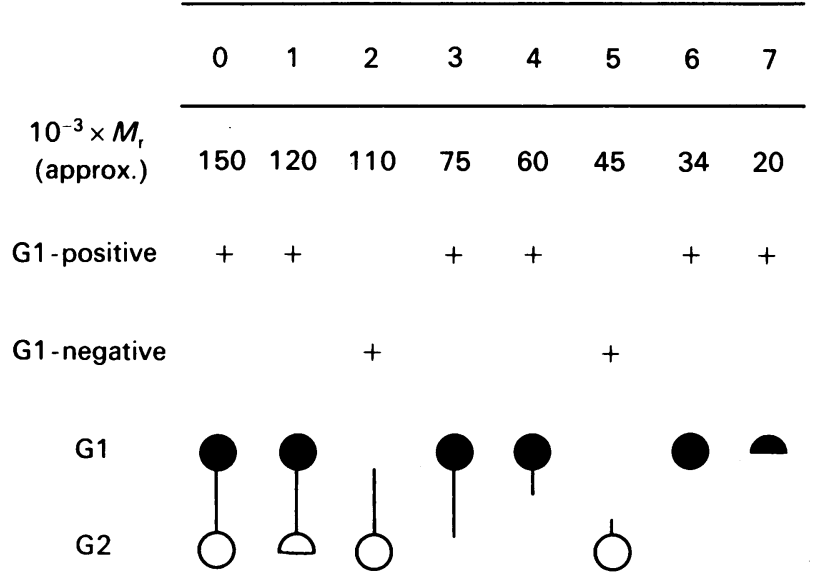

Fig. 5. Schematic representation of the G1-G2 fragment structures produced by V8-proteinase digestion

The proposed composition and approximate $M_{\mathrm{r}}$ of the fragments are shown. The numbers of fragments (0 to 7) correspond to the peak numbers given in Fig. 4. G1positive fragments are those that contain Gl, and Glnegative fragments are those that do not.

ester bonds specifically at the carboxy end of glutamic acid and aspartic acid residues (Drapeau et al., 1972). ${ }^{125}$ I-labelled G1-G2 was digested with three concentrations of V8 proteinase (Figs. $4 a-4 c$ ), and portions of each digest were immunoprecipitated with anti-Gl serum in order to separate fragments containing Gl epitopes (G1-positive) from those that did not (G1-negative). The total digests were run on SDS/polyacrylamide-gel electrophoresis (Figs. $4 a-4 c$ ) and were compared with the immunoprecipitated (G1-positive) fragments and those that remained in the supernatant that were run separately (Figs. $4 d-4 f$ ). The total digests showed a progressive decrease in the size of the fragments produced with increasing concentrations of V8 proteinase. At the lowest concentration, immunoprecipitation with anti-G1 serum identified undegraded G1-G2 (structure $0, M_{\mathrm{r}}$ 150000; Fig. 5) and a major fragment of $M_{\mathrm{r}}$ approx. 60000 (Fig. 4d, peak 4). At a 10-fold greater concentration of $\mathrm{V} 8$ proteinase (Figs. $4 b$ and $4 e$ ) the G1 fragments were present almost entirely as $75000-M_{\mathrm{r}}$ and $34000-M_{\mathrm{r}}$ products (Fig. $4 e$, peaks 3 and 6 respectively), and at a 100 -fold greater concentration of enzyme (Figs. $4 c$ and $4 f$ ) Gl was present as $34000-M_{\mathrm{r}}$ and smaller products (Fig. $4 f$, peaks 6 and 7 respectively).

At the lowest concentration of V8 proteinase, most of the binding-region-negative (G1-negative) material, i.e. that which was not immunoprecipitated by anti-G1 serum, was present as a large fragment $\left(M_{\mathrm{r}} 110000\right)$, which corresponded to the G1-G2 fragment less the G1 domain. With increasing amounts of $\mathrm{V} 8$ proteinase the $110000-M_{\mathrm{r}}$ fragment was converted into a $45000-M_{\mathrm{r}}$ fragment (Figs. $4 e$ and $4 f$ ). Fig. 5 shows schematically the proposed composition of the fragments generated by V8proteinase digestion of $\mathrm{G} 1-\mathrm{G} 2$ as deduced from the results shown in Figs. $4(d)-(4 f)$.

\section{Isolation of G2 from the G1-G2 fragment and} preparation of anti-G2 serum

The G1-G2 fragment was digested with V8 proteinase, and excess hyaluronate was added. Size-exclusion

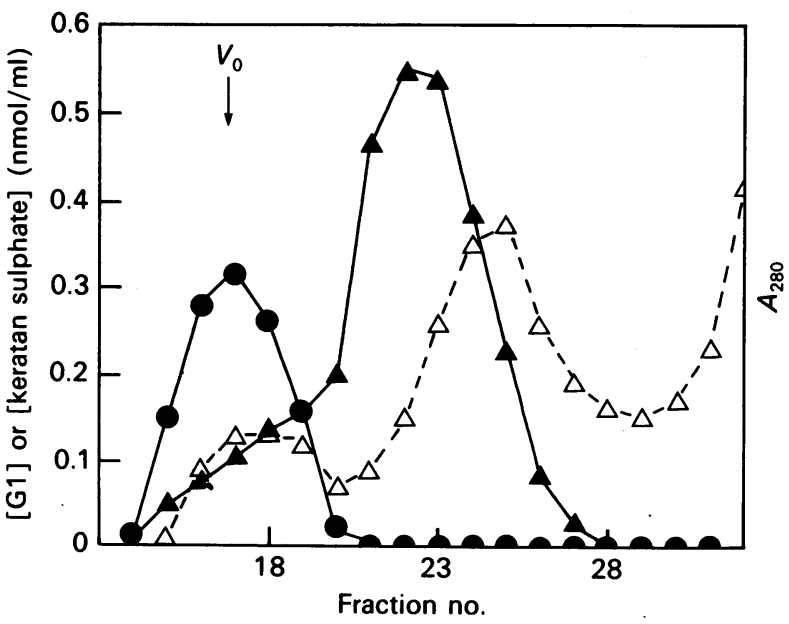

Fig. 6. Isolation of $\mathbf{G} 2$ on TSK-4000

G2 was cleaved from purified G1-G2 fragment by V8 proteinase, and purified from G1 by h.p.l.c. on TSK -4000

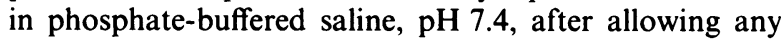
fragments containing $\mathrm{Gl}$ to bind to added hyaluronate. The column was monitored for $A_{280}(\triangle)$ and the fractions were assayed for $\mathrm{Gl}(\boldsymbol{O})$ and keratan sulphate $(\Delta)$ by radioimmunoassay.

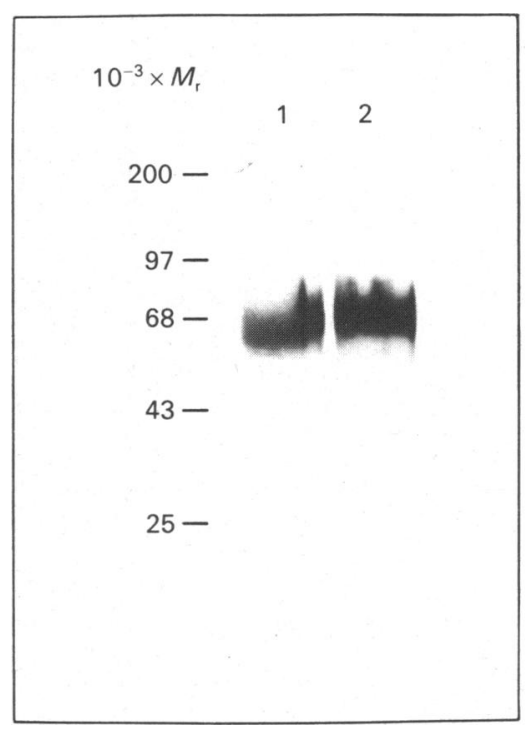

Fig. 7. SDS/polyacrylamide-gel electrophoresis of purified G2

Purified G2, which had been prepared by digesting $1.18 \mathrm{mg}$ of keratanase-digested $\mathrm{G} 1-\mathrm{G} 2$ with 0.858 unit of V8 proteinase (final volume $800 \mu \mathrm{l}$ ) and isolated on an associative TSK -4000 column as described in the text, was subjected to SDS $/ 7.5^{\circ}$-polyacrylamide-gel electrophoresis in the presence (track 2) or in the absence (track 1) of 2-mercaptoethanol. Protein bands were detected by silver staining.

chromatography on a TSK -4000 column separated components containing $\mathrm{G} 1$ that were bound to hyaluronate, which were excluded from the column, from G2, which was included in the column (Fig. 6). The elution profile of keratan sulphate epitope on the TSK 4000 column suggested that the $\mathrm{G} 2$ fragments released were a hetero- 


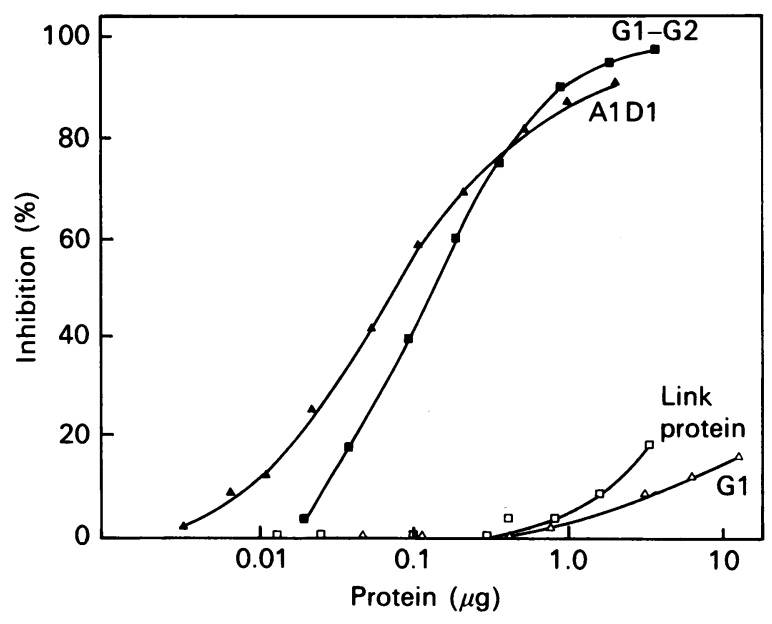

Fig. 8. Specificity of rabbit polyclonal antiserum to G2

A rabbit polyclonal anti-G2 serum was tested for specificity by comparing competitive binding of A1D1 ( $\Delta), \mathrm{G} 1-\mathrm{G} 2$ $(\square)$, link protein $(\square)$ and $G 1(\triangle)$ in a radioimmunoassay. Dilutions of each competitor $(100 \mu \mathrm{l})$ were incubated overnight at room temperature with 1:50 dilution of ${ }^{125} \mathrm{I}$ G1-G2 (keratanase-digested) and 1:80 dilution of antiserum.

geneous population with some containing much more keratan sulphate epitope than others. After keratanase digestion, which removes about $90 \%$ of the keratan sulphate epitope, G2 migrated as a single band on SDS $/ 7.5 \%$-polyacrylamide-gel electrophoresis with an apparent $M_{\mathrm{r}}$ of 66000 for the native molecule and $M_{\mathrm{r}}$ 70000 under reducing conditions (Fig. 7). The slight increase in apparent size on reduction showed the $G 2$ fragment to contain a single polypeptide without internal cleavages.

The $66000-M_{\mathrm{r}}$ fragment isolated was thus identified as containing $\mathrm{G} 2$, as it was derived as a large fragment of G1-G2 and did not contain any antigenic determinants found on G1. The increase in mobility on electrophoresis showed it to be at least partially globular. Further experiments have shown it to react with a monoclonal antibody 1-C-6 (Hejna et al., 1987), which has been reported to recognize a peptide sequence found in $\mathrm{Gl}$ and repeated in G2 in the rat. Reaction of antibody 1-C6 with G2 only occurred after reduction and keratanase digestion (A. J. Fosang \& T. E. Hardingham, unpublished work). The $66000-M_{\mathrm{r}}$ fragment thus contained a buried epitope recognizable by antibody $1-C-6$ but none of the major antigenic determinants found on $\mathrm{Gl}$, and it must therefore contain at least a major part of the G2 domain.

A rabbit polyclonal anti-G2 serum was raised against purified pig G2. It showed specificity for G2 and did not cross-react with other proteoglycan components after electrophoresis and immunoblotting (results not shown). Link protein and G1 showed only low levels of competition at high concentrations $(30 \mu \mathrm{g} / \mathrm{ml})$ in a radioimmunoassay of G2 (Fig. 8). The major epitopes on G2 were therefore absent from $\mathrm{Gl}$ and link protein. The antiserum appeared to be species-specific and did not show significant cross-reactivity with dog or human proteoglycan monomer, before or after keratanase digestion (results not shown).
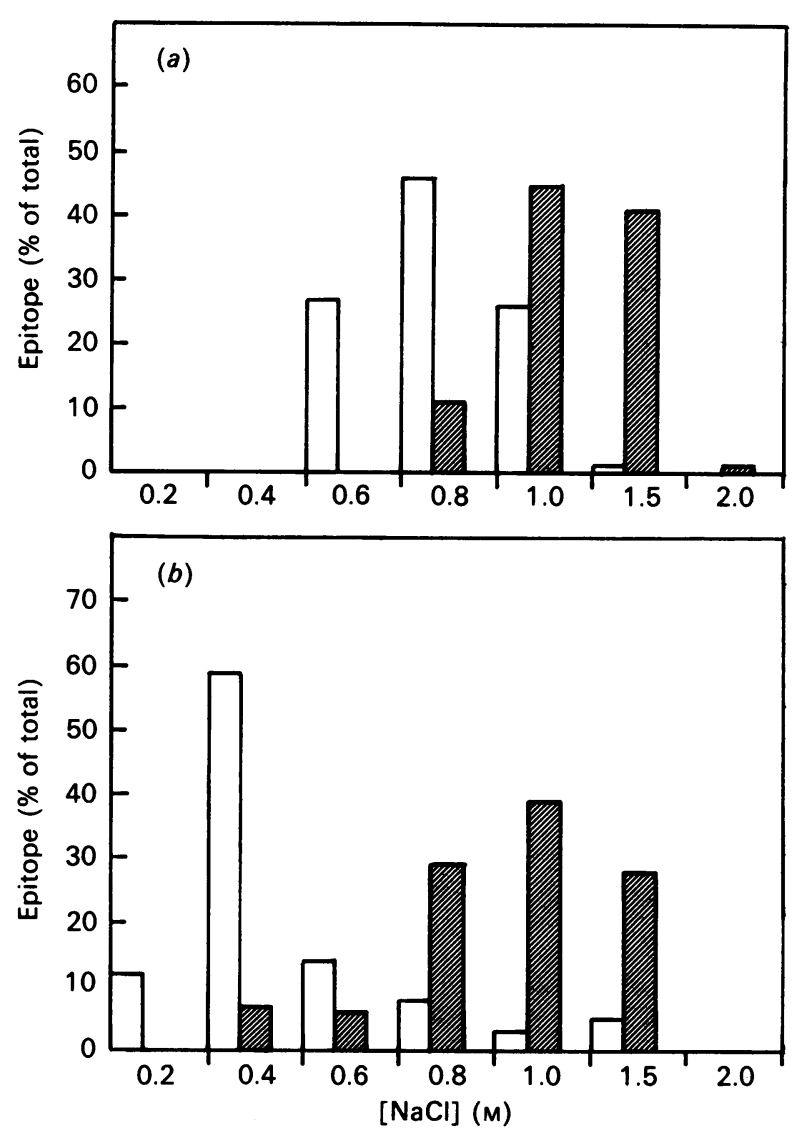

Fig. 9. Purification of $\mathbf{G 2}$ by ion-exchange chromatography

G2 was prepared as described in the Materials and methods section $(a)$ or prepared from keratanase-digested G1-G2 (b) as shown in Fig. 7 and applied to a DEAE-Sephacel column. The sample was eluted in a stepwise manner in $50 \mathrm{~mm}$-sodium acetate buffer, $\mathrm{pH} 6.8$, containing $0.2 \mathrm{M}$ - to $2.0 \mathrm{M}-\mathrm{NaCl}$ and assayed for $\mathrm{G} 2$ epitope $(\square)$ and keratan sulphate epitope (盾). The residual keratan sulphate epitope present on keratanase-treated G2 represents $10 \%$ or less of the total keratan sulphate that was present on G1-G2 before keratanase digestion.

\section{Ion-exchange fractionation of $\mathbf{G 2}$}

Keratanase-digested G2 was fractionated by ionexchange chromatography and the fractions were monitored for $\mathrm{G} 2$ by using a radioimmunoassay (see below) and for residual keratan sulphate epitopes (Fig. 9b). The fraction that was eluted from DEAE-Sephacel with $0.4 \mathrm{M}-\mathrm{NaCl}$ contained $60 \%$ of the $\mathrm{G} 2$ epitopes and only $7 \%$ of the total keratan sulphate epitope, whereas fractions eluted at salt concentrations at and above $0.8 \mathrm{M}$ contained $86 \%$ of the keratan sulphate epitope and only $15 \%$ of $\mathrm{G} 2$. The results show that a small proportion of $\mathrm{G} 2(<10 \%)$ contains some keratan sulphate epitope that is resistant to keratanase digestion. In comparison, the elution of $\mathrm{G} 2$ untreated with keratanase was in the region of $0.6 \mathrm{M}-$ and $0.8 \mathrm{M}-\mathrm{NaCl}$ (Fig. 9a). This indicated that all G2 fragments contained some keratan sulphate, even though the $0.6 \mathrm{M}-\mathrm{NaCl}$ fraction contained no detectable keratan sulphate epitopes. The monoclonal antibody has been shown to recognize an oversulphated keratan sulphate sequence (Mehmet et al., 1986), and this may be absent from these keratan sulphate chains. 
Table 1. Interaction of ${ }^{125}$ I-labelled G1-G2 and ${ }^{125}$ I-labelled G2 with proteoglycan and cartilage components

${ }^{125}$ I-labelled G1-G2 or ${ }^{125}$ I-labelled G2 was allowed to interact with either proteoglycan monomer with or without hyaluronate with or without link protein, or A2 fraction, or A3 fraction (density-gradient fractions containing cartilage matrix proteins), or type II collagen, and eluted on an associative TSK -4000 column as described in the Materials and methods section. The binding was determined from the shift in the radioactivity of the labelled component to the $V_{0}$ of the column.

\begin{tabular}{lcc}
\hline & $\begin{array}{c}\text { Binding of } \\
\text { 125I-G1-G2 } \\
(\%)\end{array}$ & $\begin{array}{c}\text { Binding of } \\
\text { Components }\end{array}$ \\
\hline $\begin{array}{l}\text { Proteoglycan monomer } \\
\text { Proteoglycan + hyaluronate }\end{array}$ & 22 & 1 \\
Proteoglycan + hyaluronate & 76 & 2 \\
$\quad$ link protein & 88 & 2 \\
A3 fraction & 72 & 1 \\
A2 fraction & 41 & 1 \\
Type II collagen & 0 & 0 \\
\hline
\end{tabular}

\section{Interaction of $\boldsymbol{N}$-terminal globular domains with extracted cartilage components}

Link protein and $\mathrm{Gl}$ are known to have a role in aggregate formation by their non-covalent binding to both hyaluronate and each other. Since G2 also contained a sequence similarity (Neame et al., 1987; Doege et al., 1987) to the tandem repeat found in $G 1$ and link protein, it was expected that G2 might share some of their functional properties. The ability of ${ }^{125}$ I-labelled G1-G2 fragment and ${ }^{125}$ I-labelled $\mathrm{G} 2$ to interact with hyaluronate in the presence of link protein and proteoglycan monomer was investigated by mixing the components under associative conditions and chromatographing on a TSK-4000 column. Similar experiments were performed with type II collagen and a mixture of $4 \mathrm{M}$-guanidinium chloride-extractable cartilage matrix components from which most of the proteoglycan had been removed. ${ }^{125} \mathrm{I}$ labelled G1-G2 showed a low degree of interaction with proteoglycan $(22 \%)$, but a high proportion bound with proteoglycan and hyaluronate $(76 \%)$, and even more with proteoglycan, hyaluronate and link protein $(88 \%)$. These results showed the ability of $\mathrm{G} 1-\mathrm{G} 2$ to participate in the interactions of aggregation. In contrast, ${ }^{125} \mathrm{I}-$ labelled G2 showed negligible interaction (1-2\%) with any of these components, indicating that $G 2$ has no affinity for link protein, proteoglycan (or G1) or hyaluronate. It thus had no properties comparable with those of isolated G1 (Bonnet et al., 1985) or the G1-G2 fragment. ${ }^{125} \mathrm{I}$-labelled $\mathrm{G} 1-\mathrm{G} 2$ also showed interaction with mixed matrix protein fractions A2 (41\%) and A3 $(72 \%)$, as these contained variable proportions of free link protein and free hyaluronate as well as other matrix macromolecules. The labelled $\mathrm{G} 2$ fragment showed no interaction with A 2 or A3 fractions, and it therefore had no detectable binding with other extracted matrix proteins.

Identical interaction experiments were also performed with non-radiolabelled keratanase-digested G2 as described in the Materials and methods section. In each case there was no interaction of $\mathrm{G} 2$ with any of the components tested, indicating that the iodinated protein showed properties that were similar to those of the noniodinated protein. The binding of $\mathrm{G} 1-\mathrm{G} 2$ to link protein and hyaluronate therefore appears to be mediated exclusively through the G1 domain (Table 1). Neither G1-G2 nor G2 showed detectable binding to pepsindigested type II collagen.

\section{DISCUSSION}

The sequence data show that considerable similarity exists between the primary and secondary structures of G1, G2 and link protein (Neame et al., 1987; Doege et al., 1987; Perkins et al., 1989). A double-loop structure for each of G1, G2 and link protein has been proposed, as well as an Ig fold, which is present in Gl and link protein. Both $\mathbf{G l}$ and link protein interact specifically with a decasaccharide segment of hyaluronate and also bind to each other (Hardingham \& Muir, 1973; Hascall \& Heinegård, 1974; Bonnet et al., 1985; Périn et al., 1987). The present results show that in spite of containing a double-loop structure the G2 domain does not have any binding properties similar to those of G1 or link protein. Furthermore, it also shows no evidence of binding with type II collagen or guanidinium chloridesolubilized cartilage matrix proteins. The lack of interaction of $\mathrm{G} 2$ with link protein or hyaluronate is entirely compatible with rotary-shadowing electronmicroscopic studies (Paulsson et al., 1987; Mörgelin et al., 1988) on the G1-G2 fragment that suggested that only one globular domain G1 was involved in binding to hyaluronate and link protein. The non-binding globular domain is thus identified as G2.

Although the $\mathrm{G} 2$ domain contains similar sequences to those found in G1 and link protein, the polyclonal antiserum raised against it did not show cross-reaction with G1 or link protein. It has previously been shown that polyclonal anti-G1 and anti-(link protein) sera also showed no cross-reaction between their respective antigens (Ratcliffe \& Hardingham, 1983). Thus, in spite of containing similar sequences, they are certainly not identical and the differences in sequence must be sufficient to ensure that the major antigenic determinants are unique to each protein structure and not shared with the related proteins.

The results reveal no function for $\mathrm{G} 2$ or offer no reason for the presence of a partial repeat of $G 1$ in a separate $\mathrm{G} 2$ domain. It may act as a structural element that helps separate the major glycosaminoglycan-bearing region from the site of aggregation and thereby make it more favourable to aggregation. It may present a site for proteolysis involved in turnover of the extracellular matrix. Studies of the fragments produced in turnover have shown cleavage close to $\mathrm{G} 2$ to be a common early site of attack (Ratcliffe et al., 1986). As the G1 domain has been shown to be fully competent for stable interaction with hyaluronate and link protein and the present results detect no comparable activities in $\mathrm{G} 2$, it would appear that the $\mathbf{G} 2$ domain is not involved in proteoglycan aggregation or interaction with other cartilage matrix proteins.

We thank Mr. David Dunham for excellent technical assistance. We are grateful to the Arthritis and Rheumatism Council and the Medical Research Council for support. 


\section{REFERENCES}

Bonnet, F., Dunham, D. G. \& Hardingham, T. E. (1985) Biochem. J. 228, 77-85

Bonnet, F., Périn, J.-P., Lorenzo, F., Jollès, J. \& Jollès, P. (1986) Biochim. Biophys. Acta 873, 152-155

DeBlas, A. L. \& Cherwinski, H. M. (1983) Anal. Biochem. 133, 214-219

Doege, K., Fernandez, P., Hassell, J. R., Sasaki, M. \& Yamada, Y. (1986) J. Biol. Chem. 261, 8108-8111

Doege, K., Sasaki, M., Horigan, E., Hassel, J. R. \& Yamada, Y. (1987) J. Biol. Chem. 262, 17757-17767

Drapeau, G. R., Boily, Y. \& Houmard, J. (1972) J. Biol. Chem. 247, 6720-6726

Fairbanks, G., Steck, T. L. \& Wallach, D. F. H. (1971) Biochemistry 10, 2606-2616

Farndale, R. W., Sayers, C. A. \& Barrett, A. J. (1982) Connect. Tissue Res. 9, 247-248

Grant, M. E., Ayad, S., Kwan, A. P. L., Bates, G. P., Thomas, J. T. \& McClure, J. (1988) in The Control of Tissue Damage (Glauert, A. M., ed.), pp. 3-28, Elsevier, Amsterdam, New York and Oxford

Greenwood, E. C., Hunter, W. M. \& Glover, J. S. (1963) Biochem. J. 89, 114-123

Halberg, D. F., Proulx, G., Doege, K., Yamada, Y. \& Drickamer, K. (1988) J. Biol. Chem. 263, 9486-9490

Hardingham, T. E. (1979) Biochem. J. 177, 237-247

Hardingham, T. E. \& Muir, H. (1972) Biochim. Biophys. Acta 279, 401-405

Hardingham, T. E. \& Muir, H. (1973) Biochem. J. 135, 905-908

Hardingham, T. E., Ewins, R. J. F. \& Muir, H. (1976) Biochem. J. 157, 127-143

Hardingham, T. E., Beardmore-Gray, M., Dunham, D. G. \& Ratcliffe, A. (1986) Ciba Found. Symp. 124, 30-46

Hascall, V. C. \& Heinegård, D. (1974) J. Biol. Chem. 249, 4241-4249

Received 16 December 1988/24 February 1989; accepted 3 March 1989
Heinegård, D. \& Hascall, V. C. (1974) J. Biol. Chem. 249, $4250-4256$

Hejna, M., Kimura, J., Caterson, B., Hascall, V., Stevens, J., Oike, Y., Tripier, D. \& Handley, C. (1987) Fed. Proc. Fed. Am. Soc. Exp. Biol. 46, 1961

Mehmet, H., Scudder, P., Tang, P. W., Hounsell, E. F., Caterson, B. \& Feizi, T. (1986) Eur. J. Biochem. 157, 385391

Miller, E. J. (1972) Biochemistry 11, 4903-4909

Mörgelin, M., Paulsson, M., Hardingham, T. E., Heinegård, D. \& Engel, J. (1988) Biochem. J. 253, 175-185

Morrissey, J. H. (1981) Anal. Biochem. 117, 307-310

Neame, P. J., Christner, J. E. \& Baker, J. R. (1987) J. Biol. Chem. 262, 17768-177.78

Oldberg, A., Antonsson, P. \& Heinegärd, D. (1987) Biochem. J. 243, 255-259

Patthy, L. (1987) J. Mol. Biol. 198, 567-577

Paulsson, M., Mörgelin, M., Wiedemann, H., BeardmoreGray, M., Dunham, D., Hardingham, T., Heinegärd, D., Timpl, R. \& Engel, J. (1987) Biochem. J. 245, 763-772

Périn, J.-P., Bonnet, F., Thurieau, C. \& Jollès, P. (1987) J. Biol. Chem. 262, 13269-13272

Perkins, S. J., Nealis, A., Dudhia, J. \& Hardingham, T. E. (1989) J. Mol. Biol. 206, 737-754

Ratcliffe, A. \& Hardingham, 'T. (1983) Biochem. J. 213, 371378

Ratcliffe, A., Tyler, J. A. \& Hardingham, T. E. (1986) Biochem. J. 238, 571-580

Ratcliffe, A., Doherty, M., Maini, R. N. \& Hardingham, T. E. (1988) Ann. Rheum. Dis. 47, 826-832

Sai, S., Tanaka, T., Kosher, R. A. \& Tanzer, M. L. (1986) Proc. Natl. Acad. Sci. U.S.A. 83, 5081-5085

Wiedemann, H., Paulsson, M., Timpl, R., Engel, J. \& Heinegård, D. (1984) Biochem. J. 224, 331-333

Zanetti, M., Ratcliffe, A. \& Watt, F. M. (1985) J. Cell Biol. 101, 53-59 